\title{
MELODY AS A FACTOR OF VOCAL AND PERFORMING INTERPRETATION OF THE OPERA IMAGE
}

\author{
Chen Xiao \\ Postgraduate Student, Odesa National Music Academy \\ named after A. V. Nezhdanova, Ukraine \\ e-mail: thensyao21@ukr.net, orcid.org/0000-0001-9589-2512
}

\section{Summary}

The aim of the article is to determine current approaches to the phenomenon of opera melodics, clarify the concept of opera melody, substantiate the priority of vocal and performing interpretation in the formation of an opera image and in the development of an opera musical text. A comprehensive methodology for studying the genre nature of opera and its typological artistic features is proposed. The combination of textual and semantic approaches makes it possible to expand the understanding of the melodic functions of an opera text and its communicative tasks. The scientific novelty of the research is due to the identification of aesthetic, structural and compositional, artistic and psychological prerequisites for the creation of the theory of opera melos as an autonomous discipline that can influence modern opera studies and the creative practice of opera performers. The conclusions of the article indicate the key properties of the opera melody, which make it possible to characterize it as a way of creating an opera speech; emphasize the main factors of the opera melodic speech: the enlargement of the elements of the theme and the strengthening of its discreteness, the altitude-rhythmic fixation of the motivational relief, which makes it possible to convey the sound and content of the word, orientation on the "image of feeling", emotional fullness and psychological personal reasoning, the requirement of getting used to and rebirth into an opera image and specific timbre predestination, that is, being attached to a certain type of vocal voice.

Key words: opera melody, opera speech, opera text, theory of opera melody, European opera melos.

\section{DOI: https://doi.org/10.23856/4616}

\section{Introduction}

Mastering the repertoire of European opera, in particular, compositions of the classical and romantic periods of the history of European music, is the basis for the education of opera singers, including Chinese opera singers. Through this repertoire, they discover the importance of studying such an important component of an opera composition, which is melody.

Despite the fact that with respect to the melodic structure of opera, Chinese musicians have already accumulated a certain research experience (Jan Bibo, 2005; Wu Jining, 2008; Zheng Jing, 2013; Zhu Lu, 2012), today there are still a number of unsolved problems of vocal performing understanding and recreation of the image content of the European opera melos.

In general, the theory of opera melody is in a state of development, especially from its vocal and performing side; this is due to the complexity of the history and theory of musical melos as a whole, to which B. Asafiev pointed out (B. Asafiev, 1963). The traditional teaching about musical forms (Y. Tyulin, 1974) does not allow finding all the approaches to opera melody necessary for a vocalist-interpreter. Therefore, the textological approach is more 
productive, which, on the one hand, is characterized by analytical depth and consistency, and on the other hand, - by the integrity and breadth of coverage of the factors of musical art (M. Aranovsky, 1969; A. Samoilenko, 2002). To this day, E. Kurt's research remains relevant, which allows one to approach opera art as a synergetic phenomenon, to find a certain relay race of ideas between the works of an outstanding Austrian scientist and the positions of modern musicologists, in particular those who develop ideas about the artistic interpretive tasks of vocalists-performers of opera parties.

The main aim of this article is to determine the most productive approaches to opera melody as a special genre and compositional phenomenon that is at the center of vocal and performing interpretation. An important aspect of the work is the illumination of the originality of the opera melos in connection with specific image musical and performing positions.

Some modern studies (O. Sheludyakova, 2006) make it possible to activate the semantic approach to the melodic content of the opera, to the principles of the melodic construction of the opera text, to confirm the fact that opera poetics in its historical formation is not only closely related to the phenomenon of melody, but also contributes a lot to its semantic individualization. Based on this, the study of opera melos allows us to improve musicological approaches to the melodic properties and possibilities of music in general.

The concept of melody remains today a single and general indication of the organization of musical matter, adjacent to the category of melodics, and this category is positioned as a universal of the musical and creative process. O. Sheludyakova even claims that melodics was the primary, primordial way of being music as an utterance; although it has changed over the centuries-old history of music (in accordance with the understanding of music in each of the eras), it has always remained the leading constructive musical principle, combining the experience of preclassical and classical-romantic periods in the evolution of various European genre forms, including opera (O. Sheludyakova, 2006).

\section{Genre originality of the opera melody}

The genre nature of opera has always been distinguished by its particular complexity, revealing not just a synthesis of various types of arts, but their internal intonational and meaningful unity, and this means the common roots of image processes that are realized in various artistic and linguistic ways. The historical period associated with the active development of the opera genre coincides with the time of European culture, when its main subject is the communicative abilities of the human person as a social being with dynamic psychological indicators, that is, the ability of a person to organize both a certain social environment, and his own consciousness, his inner the world - as a world of feelings and thoughts that have social significance and aesthetic sublimity. According to $\mathrm{Zhu} \mathrm{Lu}$, the main thing in the opera concept, actually, as in the musical one, is "in the affirmation of the freedom of human choice, human will, human consciousness and destiny". Opera heroes are called upon to give their answers "to the harsh prohibitions of the ancient rock drama" (Zhu Lu, 2012: 22-23). At the same time, it should be noted that in relation to opera plots, starting with the compositions of K. Monteverdi and G. Purcell and ending with the compositions of I. Stravinsky and K. Penderetsky, the original dramatic and tragic prototypes acquire new semantic positions due to the dominant musical form of the opera, due to which all opera heroes acquire an expressed lyrical modality.

There are several tasks that are fundamental for a musician-performer analyzing opera art; they are theoretical, but at the same time practical and expedient: tracing the evolution of ways to create the image of a hero in European opera; revealing the unity of the composers' 
approaches to understanding the image of an opera hero, which forces us to raise the question of vocal timbres as a determining condition for creating images of leading opera characters; typology of musical characters of opera heroes in the transition to the level of an image dramaturgy.

This level of the image dramaturgy reveals synthetic artistic features of opera characters, however, it allows one to be convinced of the leading role of their musical characteristics, the role-playing purpose of musical and melodic ways of creating the image of an opera hero. At this level of opera poetics study, the opposition between the general logic of the development of the plot and the stage fate of the leading characters, on which the general aesthetic structure of an opera composition - its understanding as an epic or a drama, a melodrama or a cathartic sharpened tragedy, depends.

Consequently, opera image dramaturgy is immediately formed as an internally contradictory, polyphonically conceived and carried out artistic process, all factors of which are determined by the complex socio-psychological context in which the formation of the genre form of the opera takes place, hence its main compositional features are determined.

It should be noted that the genre and semantic aspect of the opera approach can claim to be the leading one in connection with the study of the stage and musical and dramatic nature of the opera. In particular, the vocal presentation of the melodramatic aspect of the opera form, which is very essential in the compositional conditions of an opera composition, becomes the leading means of performing expression. In particular, the performance of the parts of lyrical heroines in operas by Russian and Italian composers of the XIX century is associated with special image, semantic and technical tasks that arise from the need to achieve the melodramatic effect of an opera image in the unity of its visual and auditory sides, that is, both as a visual and sound one.

The dynamic compositional and dramatic functions of the opera image can be revealed precisely at that level of study of the opera form, which is associated with the aesthetic impact of the opera stage, therefore, with the holistic semantic modeling of the opera image using movement and sound, or rather, stage movement and psychological dynamics, the aesthetic meaning of which is concentrated in the sound of the voice of the opera performer, in its melodic representation.

At this aesthetic architectonic level of the opera genre form, it is possible to encompass that systemic unity, which is opera melos - as a set of various melodic characteristics of opera characters, representing their plot and characterological functions. In this case, opera melodies appear as compositional and semantic trajectories of the development of images of opera heroes, with their culminating zones and intersection points, and this is not just the interaction of vocal voices, although they have a special opera timbre expression, but the creation of new intonational models of the human personality, capable of performing with its perfect prototypes.

It is this intonation structure of the opera language that allows us to introduce the concept of the interpretive style of the opera as a specific vocal and performing phenomenon, and also to consider the musical concept of the opera as a system of vocal and performing techniques, dramatic means. The ability of the musical and sound embodiment of an opera idea to acquire conceptual completeness pushes the vocalist's creative personality to the center of the opera text, and in the vocal intonation material to find the main features of the opera melody.

The textological approach to the opera melody allows us to determine the external and internal structural and semantic boundaries of the vocal and performing interpretation, proceeding from those intonation constants, melodic lexemes that entered the arsenal of the opera form in the process of its historical formation and effective stage existence; that means, they organized the process of a musical opera speech. 
For opera vocal speech, in its melodic quality - through which its main communicative functions appear (the melodics of the voice is the main thing in establishing the communicative status of a person, as some modern authors assert, for example O. Kataeva, 2011) - the enlargement and emotional strengthening of musical and expressive technique, up to the ultimate individualization of its meaning are the main; this artistic and functional transformation of the technique can be considered as personification - the consolidation of a certain personal and subject meaning for a specific musical technique, and this enhances the concreteness, independence of a separate intonational and melodic structure, determines its transformation into melodic thematicism.

\section{Opera melody as a semantic model}

The semantic functions of the melody in the opera are determined by its addressing, in all meanings and genre positions, to that highest state of a person's positive resonance with the world, which is defined as a state of love. The study of Zheng Jing allows us to assert that the identification of the melodic paradigm, the development of a special melodic style in the opera art of composers of the classical and romantic eras is due to the opera specification of the theme of love. Thanks to the embodiment of this theme, as the leading one and uniting all the plot twists of the opera action, the opera melody really turns out to be "the main solo musical characteristic associated with the accumulation of various semantic properties and the dialogization of stylistic material" (Zheng Jing, 2013: 37).

A Chinese musicologist, mastering the European opera tradition, suggests using the concept of "melodic theme", noting that the melodic thematic characteristic of the opera hero's image represents both the individualized side of this image and its generalized meaning. Although the semantic model of the opera as a whole is broader and more diverse than the image and semantic confinement of the melodic theme, the conceptual orientation of the opera concept, its ideological concretization entirely depends on the individual interpretation of the "melodic appearance" of the main character (Zheng Jing, 2013: 149-150). According to her observation, the theme of love is realized in the opera as a musical and melodic one, expressed by means of musical stylistics, and it directly embodies the image of an opera character, connecting to it all the means of intonation context. "In connection with the development of the theme of love in opera, the subject of action is the human voice - his ability to individually freely operate with his own voice, as well as individual timbre roles, specific timbre qualities of the characters that oppose the general timbre choral or orchestral side of the opera" (Zheng Jing, 2013: 163).

Turning to the analysis of opera compositions, Zheng Jing pays special attention to the leitmotif system of the opera text, thanks to which the melodic theme is able to act not only as a semantic component of an opera composition, but also as a separate representative, which, most often, acquires personified features.

An important observation is that the melodic material of the opera reveals immanent aesthetic and dramatic patterns associated with the interaction of the verbal and musical factors of the characters' opera speech. It is also significant to note that a kind of "horizontal polystylistics" or horizontal alignment and antitheticality of contrasting stylistic complexes, which serve to reveal the psychological polyphony of the leading opera images, appears in the opera melos. At the same time, musical sound is capable of performing the functions of poetic generalization, and the opera melody concentrates and in a peculiar way transforms (which is also facilitated by the performing vocal interpretation) the semantic functions of verbal communication. 
Thus, the communicative and semantic functions of the opera melody in a peculiar way dialogize with each other and with the opera composition as a procedural whole. From the point of view of the specifics of the opera image - as the arising not only in the musical sound, but as acquiring the main artistic indicators, the leading properties of opera melodic themes are:

- clarity and accuracy of articulation, dynamism and uplifting, emotional brightness of the musical material (and its presentation), some "enlargement" of the artistic stroke and aesthetic experience;

- inclusion in the whole opera narration, that is, the correspondence of the timbre gradations of the voice, freedom and measure of the performing interpretation to the general plot logic and verbal and musical drama of the composition;

- individualization of musical presentation, in the context of a stage presentation, an opera image.

Together, these aspects of the vocal and performing interpretation provide the persuasiveness of the musical and image opera conception.

\section{Conclusions}

The sphere of opera melodics reveals a complex character, since it includes a variety of stylistic figures and semantic formulas, not only of vocal, but also of mixed, vocal and instrumental origin. Nevertheless, its distinctive feature always remains the dominant vocal and instrumental intonation, moreover, of an individualized solo nature, easily allowing deviations from the canonical techniques and methods of musical speech. At the same time, opera melodic speech is strictly ordered, that means, it follows the established rules for constructing an opera text, starting with the choice of timbre and techniques of articulation, vocal breathing (voice production) and ending with types of opera characters that also imply stable ways of stage behavior.

An opera melody is characterized by: reliance on the horizontal (subordination of vertical regularities to it), enlargement of the elements of the theme, increased discreteness in order to increase the expressiveness of individual intonations; clarity, high-altitude-rhythmic fixation of the motive relief, which allows, among other things, to clearly convey the sound and content of the word, which is an indispensable part of opera speech, even in the case of its extreme musical and artistic freedom; orientation to sensory experience, to the "image of feeling", first of all, therefore, emotional fullness and psychological personal argumentation, the requirement of empathy from each performer - as not just "reincarnation", but getting used to and rebirth into an opera image; timbre predestination, that is, the attachment to a certain type of vocal voice, hence the attachment to the human personality with its typical, albeit evolving, features and properties.

It is the latter circumstance that allows us to perceive the compendium of opera melodic themes as a kind of encyclopedia of human characters and relationships, emotional projections and ways of experiencing. In its given role, the opera melody captures the highest aesthetic qualities of a person as a socialized active subject.

\section{References}

Aranovskiy, M. (1969). Melodika S. Prokof'yeva [Melodic S. Prokofiev]. Leningrad. [in Russian]. Asaf'yev, B. (1963). Muzykal'naya forma kak protsess: Kn.1-2. [Musical form as a process: Book 1-2]. Leningrad: Muzgiz, Leningr. otdeleniye. [in Russian]. 
Dzhan, Bibo. (2005). O znachenii verbal'noy simvoliki v muzyke [On the meaning of verbal symbolism in music]. Musical art and culture: Science newsletter ODMA im. A.V. Nezhdanovoy: zb. sciences. articles. Odessa: Drukarskiy dim. Vip. 6. Kn. 2. P. 142-151. [in Russian].

Katayeva, O. (2011). Kommunikativnyye osnovy melodiki golosa lichnosti. [Communicative foundations of personality voice melody]. URL: http://www.analiculturolog.ru/journal/archive/ item/622-communicative-framework-melodic-voice-personality.html [in Russian].

Kurt, E. (1975). Romanticheskaya garmoniya i yeye krizis v «Tristane» Vagnera. [Romantic harmony and its crisis in Wagner's Tristan]. Moscow: Muzyka. [in Russian].

Levasheva, O. (1980). Puchchini i yego sovremenniki. [Puccini and his contemporaries]. Moscow: Sovetskiy kompozitor. [in Russian].

Samoylenko, A. (2002). Dialog kak muzykal'no-kul'turologicheskiy fenomen: metodologicheskiye aspekty sovremennogo muzykoznaniya. [Dialogue as a musical and cultural phenomenon: methodological aspects of modern musicology]. Thesis ...Doctors of art history: spec. 17.00.03 - musical art. Odessa. [in Russian].

Tyulin, YU. (1974). Muzykal'naya forma: uchebnik. [Musicalform: textbook]. Moscow: Muzyka. [in Russian].

U, TSzinin. (2008). Semanticheskaya model' tragedii kak osnova zhanrovoy poetiki opery. [The semantic model of tragedy as the basis of the genre poetics of opera]. Thesis. ...Candidate of art history: spec. 17.00.03-musical art. Odessa. [in Russian].

Chzhen, TSzin. (2013). Tema lyubvi kak esteticheskaya i muzykal'no-intonatsionnaya paradigma opernogo zhanra. [The theme of love as an aesthetic and musical-intonational paradigm of the opera genre]. Thesis. ...Candidate of art history: spec. 17.00.03-musical art. Odessa. [in Russian].

Chzhu, Lu. (2012). Liricheskiy geroy kak muzykal'no-smyslovaya paradigma russkoy opery $X I X$ veka. [The lyrical hero as a musical and semantic paradigm of Russian opera of the 19th century]. Thesis ... Candidate of art history: spec. 17.00.03-musical art. Odessa. [in Russian]. Sheludyakova, O. (2006). Fenomen melodiki v muzyke pozdnego romantizma. [The phenomenon of melody in the music of late romanticism]. Thesis ...Doctors of art history: spec. 17.00.02musical art. Ekaterinburg. [in Russian]. 